\section{AB1117 CLINICAL IMPACT OF MUSCULOSKELETAL ULTRASOUND ON RHEUMATOID ARTHRITIS IN ROUTINE CLINICAL PRACTICE}

J. Molina Collada ${ }^{1}$, M. Pérez², I. Castrejon ${ }^{1}$, J. C. Nieto ${ }^{1}$, T. González ${ }^{1}$, J. Rivera ${ }^{1}$, C. Gonzalez ${ }^{1}$, I. Monteagudo ${ }^{1}$, J. M. Alvaro-Gracia ${ }^{1,2} .{ }^{1}$ Gregorio Marañón University Hospital, Madrid, Spain; ${ }^{2}$ Complutense University of Madrid, Madrid, Spain

Background: Musculoskeletal ultrasound (MSUS) is a useful tool to assess disease activity in rheumatoid arthritis (RA) patients. However, it has not yet been established if its use would change treatment decisions within a treat to target strategy or whether it would lead to better outcomes in RA patients

Objectives: Our aim was to determine the impact of MSUS in the clinical management of RA patients and investigate factors associated with subsequent clinical actions by the referring rheumatologist

Methods: A prospective analysis of RA patients seen at an MSUS clinic over a 6-month period was undertaken. Pre- and post-US follow-up data ( \pm 3 months) were analyzed. Baseline assessment included clinical features, physical examination and laboratory tests. All MSUS examinations were performed according to EULAR guidelines and using an Esaote MyLab 8 (Esaote, Genoa) with a high frequency $(8-15 \mathrm{MHz})$ transducer. Patients were stratified in groups based on the clinical impact of the MSUS visit: 1) No clinical impact and 2) US findings leading to subsequent clinical action by the referring rheumatologist (including changes in dosages of current rheumatologic treatments, addition/substraction of medications or interventional procedures based on the MSUS results). First, differences between groups were tested using chi-squared and Student-t tests in the univariate analysis. Second, multivariate logistic regression models were employed to investigate factors associated to a change in clinical management Results: A total of 61 RA patients were included for analysis. Mean age was $61.9 \pm 11.4$ years and $51(83.6 \%)$ were female. Disease activity assessment was the most frequent referral reason ( $43 ; 70.5 \%)$. Overall, MSUS led to a subsequent therapeutic action by the referring rheumatologist in $39(63.9 \%)$ patients, and to a change in the underlying diagnosis and/or in the clinical impression of the chief complaint that generated the referral in $7(11.5 \%)$ patients. Baseline characteristics between both groups are compared in Table 1. In the univariate analysis, the detection of Power Doppler (PD) synovitis/tenosynovitis and 28 swollen joint count were significantly associated with a subsequent clinical action. In the multivariate analysis only PD synovitis/tenosynovitis (OR=3.28; 95\% Cl 1.06-10.27) remained significantly associated with a change in clinical management (Table 2)

Table 1. Baseline characteristics of RA patients

\begin{tabular}{|c|c|c|c|c|c|}
\hline & & Total $n=61$ & $\begin{array}{c}\text { Change in clinical } \\
\text { management } n=39 \\
(63.9 \%)\end{array}$ & $\begin{array}{c}\text { No change in clinical } \\
\text { management } n=22 \\
(36.1 \%)\end{array}$ & $\mathrm{p}$ \\
\hline \multicolumn{2}{|l|}{ Age } & $61.9 \pm 11.4$ & $61.5 \pm 12.5$ & $62.6 \pm 9.2$ & 0.7 \\
\hline \multirow{4}{*}{$\begin{array}{l}\text { Sex } \\
\text { Smoking }\end{array}$} & Female & $51(83.6 \%)$ & $35(89.7 \%)$ & $16(72.7 \%)$ & 0.09 \\
\hline & Non smoker & $33(54.1 \%)$ & $17(43.6 \%)$ & $16(72.7 \%)$ & 0.08 \\
\hline & Smoker & $13(21.3 \%)$ & $11(28.2 \%)$ & $2(9.1 \%)$ & \\
\hline & $\begin{array}{l}\text { Former } \\
\text { smoker }\end{array}$ & $15(24.6 \%)$ & $11(28.2 \%)$ & $13(21.3 \%)$ & \\
\hline \multicolumn{2}{|c|}{ Radiographic erosions } & $29(48.3 \%)$ & $22(57.9 \%)$ & $7(31.8 \%)$ & 0.05 \\
\hline \multicolumn{2}{|c|}{28 Tender Joint Count } & $2.3 \pm 3.4$ & $2.7 \pm 3.9$ & $1.6 \pm 2.4$ & 0.2 \\
\hline \multirow{2}{*}{\multicolumn{2}{|c|}{$\begin{array}{l}28 \text { Swollen Joint Count } \\
\text { ESR }(\mathrm{mm} / \mathrm{h})\end{array}$}} & $2 \pm 3$ & $2.6 \pm 3.5$ & $1.1 \pm 1.6$ & $<0.05$ \\
\hline & & $28.1 \pm 20.6$ & $26.1 \pm 15.5$ & $31.7 \pm 27.4$ & 0.4 \\
\hline \multicolumn{2}{|c|}{$\operatorname{CRP}(g / L)$} & $1 \pm 1.5$ & $1 \pm 1.4$ & $0.9 \pm 1.7$ & 0.7 \\
\hline \multicolumn{2}{|c|}{$\mathrm{RF}(\mathrm{IU} / \mathrm{mL})$} & $175.8 \pm 452.8$ & $139.9 \pm 249.5$ & $243.9 \pm 697.4$ & 0.4 \\
\hline \multicolumn{2}{|c|}{ ACPA (IU/mL) } & $775.6 \pm 998.6$ & $619.4 \pm 797.1$ & $1079.9 \pm 1,275.9$ & 0.2 \\
\hline \multicolumn{2}{|c|}{$\begin{array}{l}\text { US PD synovitis/ } \\
\text { tenosynovitis }\end{array}$} & $37(60.7 \%)$ & $28(71.8 \%)$ & $9(40.9 \%)$ & $<0.05$ \\
\hline
\end{tabular}

Table 2. Independent factors associated with a change in clinical management based on logistic regression model

\begin{tabular}{lcccc}
\hline & $\mathrm{p}$ & Odds ratio & \multicolumn{2}{c}{$95 \%$ C.I. } \\
\hline & & & Lower & Upper \\
\hline 28 Tender Joint Count & 0.13 & 1.24 & 0.94 & 1.64 \\
US PD synovitis/tenosynovitis & 0.04 & 3.28 & 1.06 & 10.17 \\
\hline
\end{tabular}

Conclusion: The most common indication of MSUS examination in RA patients was disease activity assessment. MSUS findings led frequent changes in therapeutic management and even to a change in the diagnosis in some of cases. The presence of PD synovitis/tenosynovitis was significantly associated to a change in the therapeutic management. These data highlight the impact of MSUS inflammatory findings in RA patients in daily clinical practice

Disclosure of Interests: Juan Molina Collada: None declared, María Pérez: None declared, Isabel Castrejon: None declared, Juan Carlos Nieto Speakers bureau: Pfizer, Abbvie, MSD, Novartis, Janssen, Lilly, Nordic Pharma, BMS, Gebro, FAES Farma, Roche, Sanofi, Teresa González: None declared, Javier Rivera: None declared, Carlos Gonzalez Consultant of: Gilead, Janssen, Novartis,, Speakers bureau: Abbvie, Celgene, Gilead, Janssen, Novartis, Pfizer, Roche, Indalecio Monteagudo: None declared, Jose-Maria Alvaro-Gracia Grant/research support from: Abbvie, Elli-Lilly, MSD, Novartis, Pfizer, Consultant of: Abbvie, BMS, Janssen-Cilag, Elli-Lilly, MSD, Novartis, Pfizer, Sanofi, Tigenix, Roche, UCB, Paid instructor for: Elli-Lilly, Pfizer, Roche, Speakers bureau: Abbvie, BMS, Janssen-Cilag, Elli-Lilly, Gedeon Richter, MSD, Novartis, Pfizer Sanofi, Tigenix, Roche, UCB DOI: 10.1136/annrheumdis-2020-eular.6289

\section{AB1118 $\quad$ OPEN MUSCLE BIOPSY AS A SAFE AND USEFUL MEANS OF DIAGNOSING VASCULITIS: A SINGLE- CENTER EXPERIENCE OF 210 BIOPSY CASES}

T. Mori ${ }^{1}$, N. Yokogawa ${ }^{1}$, K. Shimada ${ }^{1}{ }^{1}$ Tokyo Metropolitan Tama Medical Center, Department of Rheumatic Diseases, Tokyo, Japan

Background: We previously reported the utility of open muscle biopsies in diagnosing vasculitis [1]. The number of open muscle biopsies performed at our department has increased to over 200. The purpose of the present study was to evaluate the diagnostic utility of vasculitis and the safety of the open muscle biopsies.

Objectives: To clarify the diagnostic utility of vasculitis and the safety profile of the open muscle biopsy.

Methods: We retrospectively examined all cases of open muscle biopsy performed between May 2012 and June 2018 in our department. The biopsy results, the presence or absence of adverse events, and blood test data a the time of the biopsy were extracted from the patients' electronic medical records.

Results: Between May 2012 and June 2018, 210 open muscle biopsies were performed, 120 of which were done for vasculitis diagnosis. Diagnostic histopathological findings were obtained in 42 of the 120 cases (35\%). The definitive diagnosis in these cases was microscopic polyangiitis (30 cases), eosinophilic granulomatosis with polyangiitis (seven cases), granulomatosis with polyangiitis (one case), polyarteritis nodosa (three cases), and other vasculitis (one case). In 57 cases with myeloperoxidase-anti-neutrophil cytoplasmic antibody (MPOANCA) $\geq 10 \mathrm{U} / \mathrm{ml}$, 31 cases $(54.3 \%)$ showed histopathology of vasculitis. In six cases with protainase-3-ANCA (PR3-ANCA) $\geq 10 \mathrm{U} / \mathrm{ml}$, histopathology of vasculitis was found in one case (16.7\%).

In all 210 open muscle biopsy cases, complications included minor wound dehiscence (11 cases) and small subcutaneous hematoma (six cases), which were able to be managed by local treatment. Albumin was significantly lower in the patients with wound dehiscence (mean 3.2 vs $2.7, p=0.049$ )

Serious complications included anaphylaxis due to local anesthesia (one case), compartment syndrome due to hematoma (one case), hematoma requiring surgical removal (one case), and arterial hemorrhage requiring surgical intervention (one case). The patients in the latter three hemorrhagic cases were receiving antiplatelet drugs.

Conclusion: An open muscle biopsy is useful for diagnosing vasculitis, especially for MPO-ANCA-positive anca-associated vasculitis. Its safety profile is acceptable. Serious adverse events are rare, but the procedure should be performed carefully when patients are receiving antiplatelet drugs.

References:

[1] Nunokawa T. et al. The use of muscle biopsy in the diagnosis of systemic vasculitis affecting small to medium-sized vessels: A prospective evaluation in Japan. Scand. J. Rheumatol. 2016;45:210-214

Disclosure of Interests: None declared DOI: 10.1136/annrheumdis-2020-eular.1797

\section{AB1119 U9: A NOVEL CLINICALLY ORIENTED ULTRASONOGRAPHIC SCALE AS A USEFUL MARKER FOR MONITORING THERAPEUTIC RESPONSE IN RHEUMATOID ARTHRITIS (MULTI CENTERS STUDY)}

M. A. Mortada ${ }^{1}$, H. Eitta ${ }^{2}$, R. Elmallah ${ }^{3}$, A. Radwan ${ }^{4}$, A. Elsaman ${ }^{5} .{ }^{1}$ Zagazig University - Faculty of Medicine, Rheumatology, Zagazig, Egypt; ${ }^{2}$ AL Azhar University, Rheumatology, Cairo, Egypt; ${ }^{3}$ Ain Shams University, Rheumatology, Cairo, Egypt; ${ }^{4}$ Sohag University, Rheumatology, Sohag, Egypt; ${ }^{5}$ Sohag University, Rheumatology, Sohag, Egypt 